\title{
Materiais que geram novos materiais: uma percepção simbólica sobre os compósitos
}

\author{
Materials that generate new materials: a symbolic perception about composites
}

LIMA, Julyana; Mestranda em Design; Universidade Federal do Maranhão

julyana.slima.jl@gmail.com

NORONHA, Raquel; Professora Doutora; Universidade Federal do Maranhão

raquelnoronha79@gmail.com

SANTOS, Denilson; Professor Doutor; Universidade Federal do Maranhão

denilson.santos@ufma.br

\section{Resumo}

O desenvolvimento industrial possibilitou o aperfeiçoamento e surgimento de novos materiais para aplicação nos mais diversos produtos. Apesar dos avanços que os materiais proporcionam a nível científico e tecnológico, os estudos acerca da sua essência conferem pouca importância dentro do campo do design. Por outro lado, os compósitos, como objeto de análise específica deste artigo, tem sido alvo de intensos estudos no campo interdisciplinar dos materiais. Neste artigo, busca-se dialogar a respeito da potencialidade de materiais produzirem outros novos materiais através de suas combinações. Para tal, realiza-se uma revisão bibliográfica acerca dos compósitos e aprofundase em uma discussão além da perspectiva técnica, apresentando uma visão mais simbólica sobre a capacidade e os processos dos materiais de se reinventar, reformular e se reproduzir em resultados inusitados. Neste percurso, autores do campo do design e da antropologia contribuem com a subjetividade dos materiais e conduzem este artigo a novas percepções sobre os materiais presentes no mundo.

Palavras Chave: materiais; compósitos; subjetividade e design.

\begin{abstract}
The industrial development allowed the improvement and emergence of new materials for application in the most diverse products. Despite advances in materials provided by a scientific scientist and technologist, studies of its essence confer little importance in the field of design. On the other hand, composites, as object of article analysis, have been the subject of intense studies not interdisciplinary field of materials. In this article, we seek to dialogue about the potentiality of materials to produce other new materials through their combinations. There is a review and a bibliographical review of the analysis, presenting a more symbolic view about a material's ability and processes to reinvent itself, reformulate and reproduce in unusual results. In this course, authors of the field of design and anthropology contribute with a subjectivity of the materials and lead this article to new perceptions about the materials present in the world.
\end{abstract}

Keywords: materials; composites; subjectivity and design. 


\section{Introdução}

De modo genérico, o design integra "a fonte mais importante da maior parte da cultura material de uma sociedade que, mais do que qualquer outra sociedade que já existiu, pauta a sua identidade cultural na abundância material que tem conseguido gerar" (CARDOSO, 1998, pag. 22). As abordagens da cultura material, por sua vez, falham ao renegar ao segundo plano a temática dos materiais e suas propriedades, enfatizando em seus estudos apenas a materialidade física dos objetos. Assim, este artigo objetiva contribuir com a discussão subjetiva acerca dos materiais, focando em uma das suas possibilidades de transformação, ou seja, o compósito.

Destaca-se ainda que o design, progressivamente, tem se preocupado em corroborar com a sustentabilidade de algum modo, seja repensando o ciclo de vida dos produtos ou criando novos materiais, principalmente os fundamentados nos processos sustentáveis (FARIAS \& SANTOS, 2016). Dentre tantos estudos de casos no âmbito científico, é notória a ligação do surgimento de novos materiais ou compósitos com a problemática ambiental, sendo esta uma de suas principais justificativas.

Desse modo, o artigo discorre sobre a relevância de aprofundar-se no contexto dos compósitos sob uma perspectiva mais simbólica afim de proporcionar significativas reflexões para o campo do design. O foco é demonstrar como os designers podem ter um novo posicionamento perante os materiais/projetos por considerar a autonomia, propriedades e qualidades da matériaprima, independentemente da ação e planejamento dos profissionais, superando a sua própria materialidade. $O$ design, até mesmo no contexto prático, pode corroborar com novas posturas ao longo da preparação ou manejo dos materiais. Tim Ingold (2012) afirma a preponderância dos materiais sobre a materialidade, visto que "onde quer que olhemos, os materiais ativos da vida estão vencendo a mão morta da materialidade que tenta tolhê-los" (Ingold, 2012, p.37). Isto é, o homem trava uma batalha ao tentar conter ou manipular materiais que possuem um certo grau de autonomia e poder de autotransformação.

Alguns autores, como Ingold e Pels, têm se dedicado a estudos que demonstram como o mundo material não é passivamente subserviente aos desígnios humanos, afim de buscar um meio de reequilíbrio ao modelo hilemórfico já existente e fortemente enraizado. Em concordância com Ingold (2012), tal modelo hilemórfico reduz os materiais. Isto é, menospreza os processos de formação e destaca o produto final, abole os fluxos e transformações dos materiais e prioriza apenas os estados da matéria. Neste artigo, os materiais são explanados como elementos ativos no mundo dotados de importantes propriedades e qualidades, cuja dinâmica estimula o desenvolvimento constante de combinações de novos materiais.

\section{Sustentabilidade pelo Design}

Alguns fatores justificam a importância de estudos na temática dos compósitos, como a necessidade de inovação tecnológica ou maior consciência ambiental. Por sua vez, este artigo considera a questão ambiental como fator essencial para a inovação. Assim, a relevância da sustentabilidade aplicada aos compósitos deve ser incentivada, resultando em contribuição nos estudos em design dos materiais.

No campo do design, a sustentabilidade é aplicada através das estratégias e métodos para diminuir e/ou contornar problemas de ordem social, econômico e ambiental. Portanto, o Design 
Sustentável, conforme a Figura 1, busca maximizar os objetivos ambientais, econômicos e o aumento do bem-estar social, considerando a responsabilidade de não prejudicar o equilíbrio ambiental atual e garantir este equilíbrio às gerações futuras (PAZMINO, 2007).

Figura 1 - Tripé da Sustentabilidade

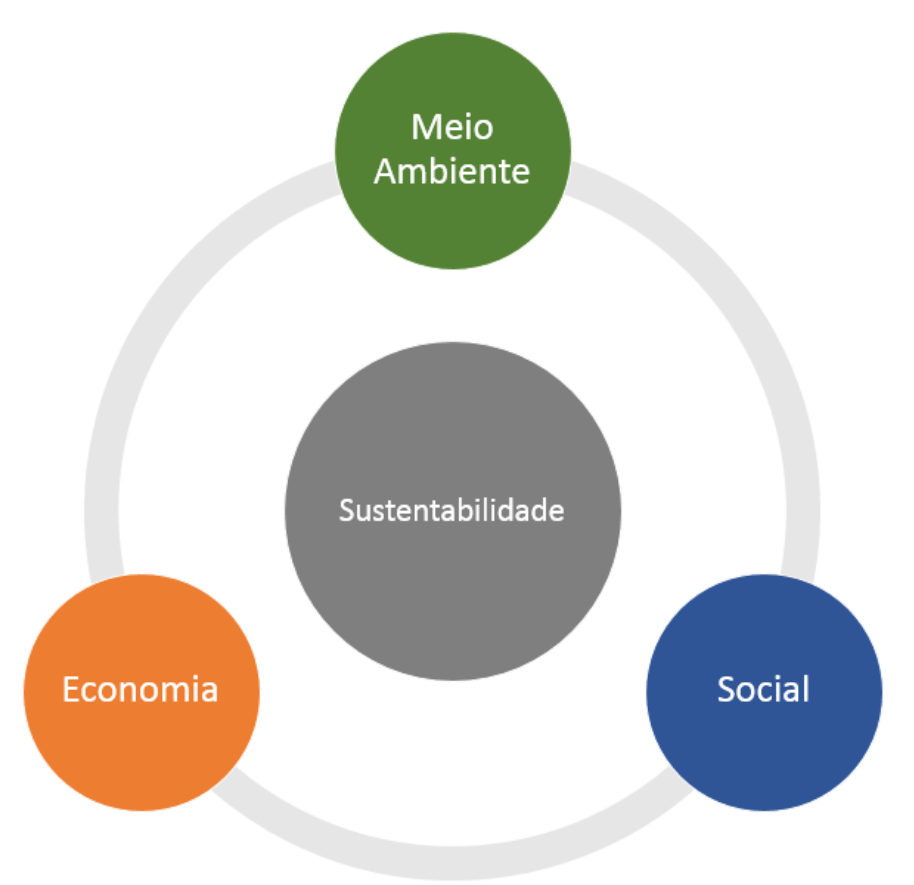

Fonte: Os autores (2018)

A sociedade tem buscado soluções mais sustentáveis para produtos e serviços. Esta demanda "requer alterações radicais nos sistemas de consumo e produção, exigindo do design novas competências e novo escopo de atuação" (SANTOS \& LEPRE, 2008, p. 2). Apesar do design almejar uma responsabilidade para com o meio ambiente desde os anos 70, apenas na segunda metade dos anos 90 o foco dos esforços foi dirigido aos produtos industriais e, consequentemente, ao design (VEZZOLI, 2007). Os produtos, neste contexto, buscavam melhorias introduzidos pelo redesign ambiental, também chamado de ecodesign.

De forma geral, o ecodesign, cuja primeira definição foi dada por Victor Papaneck nos anos 70 , trabalha com a finalidade de reduzir o impacto do ser humano no planeta. O ecodesign, como uma abordagem global, requer uma nova forma de conceber, ou seja, contemplando todas as etapas do ciclo de vida de um produto ou serviço (CAVALCANTI et al, 2012).

Todavia, os conhecimentos acerca do design para a sustentabilidade ainda hoje são pouco recorrentes na atividade do profissional do Design, justificando-se tanto pelo tempo requerido para aplicação quanto pela compreensão de que o design sustentável não é necessariamente a prioridade, mas uma das diversas variáveis que o designer pode utilizar em um determinado projeto (LOFTHOUSE, 2006). 
Vale lembrar que as várias esferas do design sustentável estimula a participação de muitas outras disciplinas, tornando inevitável uma formação dos designers ou especialização dos novos profissionais que saibam planejar, organizar e desenvolver projetos em conjunto com a comunidade (PAZMINO, 2007). A interdisciplinaridade é apresentada desde o início na história do Desenvolvimento Sustentável. Atualmente, o design se envolve cada vez mais com os conceitos de Desenvolvimento Sustentável, inovação e bem-estar social, principalmente diante as demandas da sociedade e do mercado (CAVALCANTI et al., 2012). Ressalta-se ainda que a interdisciplinaridade, de acordo com Fortes (2012, p.1), "não anula as disciplinas, mas pede que as mesmas dialoguem entre si numa perspectiva educacional em busca de inovação".

Segundo Vezzoli (2010), de forma mais ampla, o Design para a Sustentabilidade pode ser definido como uma contribuição para o desenvolvimento sustentável através da prática de design, educação e pesquisa. Assim, torna-se emergencial o fomento de pesquisas que visam o avanço sustentável em aspectos teóricos e práticos dentro do campo do design.

Para Manzini e Vezzoli (2002), o desenvolvimento de um Design para a Sustentabilidade é considerado ainda como uma espécie de design estratégico, capacitando o sistema produtivo para proporcionar o bem-estar através da utilização de uma quantidade de recursos ambientais inferior aos atuais níveis alcançados. Neste contexto, o design possui papel crucial no processo sustentável de ciclo de vida dos produtos. De acordo com Manzini (2002), tal conceito sustentável do design considera as questões ambientais e o estudo do ciclo de vida no Design de Produto, otimizando os processos e a vida útil dos produtos, tendo como ponto de convergência a redução dos impactos ambientais. Retomando à temática dos materiais deste artigo, percebe-se que antes da etapa da seleção dos materiais, a sustentabilidade deve ser ativa no ciclo de vida de um produto.

As decisões mais importantes para obtenção do design para a sustentabilidade ou design sustentável são tomadas nas primeiras fases do projeto, principalmente na fase de conceito e, por consequência, na seleção de materiais. Tais decisões possuem muita influência na redução de custos. Como Lofthouse (2004) aponta, os designers são fundamentais no que diz respeito à sustentabilidade, apresentando-se nos estágios iniciais do processo de desenvolvimento de produtos, sendo que nestes estágios as estratégias são mais flexíveis a decisões, alterações e possuem maior influência na definição de seus aspectos ambientais. Gradativamente a abordagem no desenvolvimento de novos materiais compreende todo o ciclo de vida dos produtos, considerando os impactos existentes desde a matéria-prima até o destino final do produto ou descarte (CARVALHO, 2011).

Portanto, o designer possui grande responsabilidade sobre os recursos naturais, visto que $80 \%$ do impacto ambiental dos produtos, serviços e infraestruturas no mundo são determinados por tal profissional (THACKARA, 2008). Ainda segundo Thackara (2008), as decisões de design orientam os processos por trás dos produtos, bem como os materiais e a energia necessária para produzi-los, o modo das operações no dia-a-dia e as possíveis ações após a perda de utilidade dos produtos.

As pesquisas voltadas para a sustentabilidade dos materiais têm avançado no meio acadêmico. De acordo com Beylerian e Dent (2007), já existem muitos estudos para a próxima geração de materiais, processos e ferramentas que visam o desenvolvimento de produtos orientados para a preservação ambiental. Os autores afirmam que tal inovação em materiais é nitidamente necessária para resolver algumas lacunas do futuro, sobretudo no que diz respeito às 
questões ecológicas e à escassez de materiais provenientes de fontes não renováveis.

De forma objetiva, como o design contribui para a sustentabilidade dos materiais? Segundo Pazmino (2007), a sustentabilidade relaciona-se com os materiais quando aplica diretrizes do ecodesign no desenvolvimento de produtos. Dentre elas, destaca-se: reduzir a utilização de recursos naturais e de energia, usar materiais não exauríveis (esgotáveis), usar materiais não prejudiciais (danosos, perigosos), usar materiais reciclados, usar materiais recicláveis, usar materiais renováveis, escolha de técnicas de produção alternativas, e pouca geração de resíduos.

Com este cenário, constata-se uma grande potencialidade nos compósitos, sendo estes resultados de inúmeros estudos interdisciplinares que visam a redução dos impactos ambientais no surgimento de novos produtos, a partir da combinação tanto de materiais tradicionais quanto materiais alternativos à produção industrial.

\section{Materiais}

Os avanços tecnológicos no âmbito dos materiais acarretam avanços no design, permitindo melhorias na função prática do produto ou possibilitando a criação de meios para que o design melhore as funções intangíveis (DIAS, 2009). Assim como o design permite ir além do material e criar soluções para as coisas intangíveis, o mesmo também pode se aprofundar em propriedades e aspectos da composição de determinado material. Afinal, as ideias, conceitos e projetos de um designer são concretizados através dos materiais.

De acordo com Ashby e Johnson (2010), os materiais definiram as oportunidades e os limites do design através da própria história. Ao exemplificar as épocas históricas - como a Idade da Pedra, do Bronze, do Ferro, do Plástico e do Silício (era atual) - para enfatizar a importância dos materiais, nota-se que as nomenclaturas secundárias derivam dos nomes dos principais materiais utilizados em cada era/período. Ainda segundo os autores:

\footnotetext{
Vivemos em um mundo de materiais. São os materiais que dão substância a tudo que vemos e tocamos. Nossa espécie - Homo sapiens - é diferente das outras, talvez mais significativamente pela habilidade de projetar - produzir 'coisas' a partir de materiais - e pela capacidade de enxergar mais em um objeto do que apenas a sua aparência (...). (ASHBY; JOHNSON, 2010, p. 3)
}

A Revolução Industrial proporcionou transformações na esfera cultural, social e econômica, intensificando o surgimento de materiais diversos para a produção de produtos. Neste período de aceleração da produção, "houve o impulso do design devido à necessidade de criação de produtos e o planejamento da produção com base no desenvolvimento em série" (CALEGARI \& DE OLIVEIRA, 2013).

O avanço da tecnologia e conhecimento científico tem proporcionado o surgimento de novos materiais dia após dia. De acordo com Ashby \& Jonhson (2010), existe uma gama de aproximadamente 100 mil materiais que permitem a inovação ao design, a partir da exploração imaginativa dos novos e aprimorados materiais. Segundo Beylerian e Dent (2007), os materiais podem ser considerados como uma das fontes mais ricas de inovação, uma vez que possuem potencial para promover o design inovador. 
A pesquisa em materiais que busca o aperfeiçoamento e o desdobramento de novos materiais é quase tão antiga quanto à própria humanidade, apesar de somente nos dias atuais estar em seu ápice (BEYLERIAN; DENT, 2007). O desenvolvimento da humanidade está vinculado aos materiais, por isso é imprescindível que o campo do design estimule estudos nesta área em prol de melhorias na sociedade atual.

Diversos autores abordam a evidente relação entre design e materiais. Os materiais são dissociáveis do design de produto, visto que os "materiais são a matéria de que é feito o design de produto" (ASHBY; JOHNSON, 2010, p. 55) e os "materiais são componentes físicos que constituem um produto" (GOMES, 2006, p. 151). De forma mais profunda, os "materiais podem transformar o design, e o design, portanto, tem a força para transformar nossas vidas" (BEYLERIAN \& DENT, 2007, p. 17). Ferrante e Walter (2010) afirmam que o material é o elo entre a ideia e a produção, sendo este material selecionado e processado até a reprodução física da ideia em um produto.

Os materiais são essenciais para muitas soluções de design de forma a auxiliar a execução dos requisitos propostos no projeto, podendo, inclusive, definir o leque de funções de produtos, a durabilidade, os custos, etc. Ashby \& Jonhson (2010) asseguram que o bom design é aquele que leva em consideração o uso mais eficiente dos materiais, suas propriedades e a forma como podem ser conformados. Assim, o designer é habilitado a explorar as propriedades de certo material com a finalidade de corrigir as os seus defeitos ou aperfeiçoar aspectos existentes.

Vale enfatizar que para realizar a seleção dos materiais adequados, o designer deve conhecer as opções existentes bem como algumas de suas propriedades (BEYLERIAN; DENT, 2007). Para tal, é necessário que os profissionais de design obtenham uma significativa base de conhecimento para o desenvolvimento de produtos que atendam às necessidades dos usuários de forma eficiente. Desse modo, conclui-se a importância dos estudos acerca dos materiais dentro do design de produto.

A alteração de um ou mais materiais visando redução de custos, bem como modificações da composição de um produto para um melhor desempenho técnico, são algumas das motivações que induzem empresas a aprofundarem-se na temática de seleção dos materiais. Segundo Calegari \& De Oliveira (2013), a seleção de materiais permanece presente do início ao fim do processo de design. Contudo, conforme o avanço do projeto a seleção de materiais caminha para um refinamento até a escolha efetiva do material mais adequado ao projeto.

Dentre as propriedades técnicas existentes, os designers destacam algumas muito importantes no desenvolvimento de produtos, tais como: propriedades mecânicas, resistência, dureza, acabamento, durabilidade, disponibilidade, custo, material ecológico, ergonomia, processos de fabricação. No entanto, de acordo com Calegari \& De Oliveira (2014), não cabe ao designer e seu campo de trabalho a compreensão de forma exata das propriedades técnicas, mas é válida uma noção geral do comportamento dos materiais. Segundo os estudos dos autores, as propriedades dos materiais de maneira prática são mais relevantes, ou seja, "como o material pode ser utilizado em relação aos processos de fabricação, quanto peso determinado material suporta, qual é a resistência frente a intempéries, a possibilidade de receber um determinado acabamento, a facilidade de limpeza, e outros" (CALEGARI; OLIVEIRA, 2014).

Os materiais estão presentes em diversas outras áreas do conhecimento, tal como a engenharia, e alguns casos conduzem a conhecimentos tão específicos que somente com o auxílio de profissionais especializados o produto seria desenvolvido de forma eficiente (DIAS, 2009). 
Embora o design de produto encontre relação direta aos materiais, no desenvolvimento de um produto é aconselhável a formação de uma equipe multidisciplinar.

\subsection{Compósitos}

Os materiais compósitos já possuem ampla utilização por seres humanos há alguns milênios. Os materiais compósitos, também denominados de materiais compostos, são definidos como a combinação de dois ou mais componentes, basicamente materiais puros.

De acordo com Shackelford (2012), existem três materiais tradicionais estruturais da engenharia: metais, polímeros e cerâmicos. Contudo, tais materiais estão cada vez menos suprindo as demandas de aplicações em produtos. Devido à iminente escassez destes materiais, torna-se imprescindível a busca pela redução da exploração dos mesmos.

Os compósitos podem ser classificados em uma quarta categoria de material, que abrangem uma quantidade maior de aplicações ao combinar os materiais de características divergentes entre si (CALISTER, 2008). Desse modo, o compósito proporciona a união de propriedades físicas inerentes a cada componente em um único e novo material, para que apresente o melhor desempenho estrutural em condições específicas de uso. Segundo Shackelford (2008), "o melhor dos dois mundos" deve ser o objetivo final após uma criteriosa seleção de materiais compósitos.

De forma geral, os compósitos são constituídos por uma matriz (material de liga de natureza polimérica, metálica ou cerâmica) e uma fase dispersa (partículas ou fibras que servem como carga), conforme Abreu (2015). Segundo Calister (1985), os compósitos podem ser classificados conforme o esquema abaixo:

Figura 2 - Classificação dos compósitos

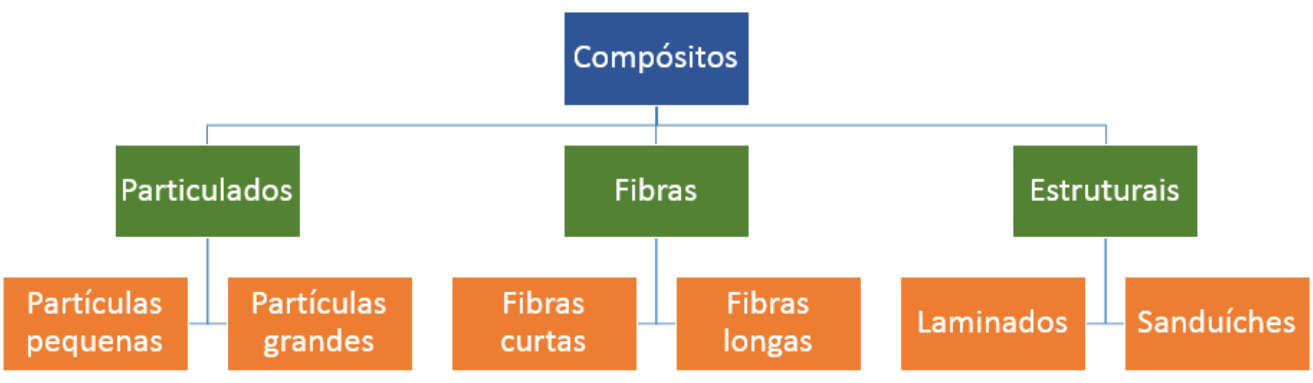

Fonte: adaptado de Calister (2008).

Conforme a Figura 2 acima, os materiais compósitos são diferenciados da seguinte forma: compósitos de fibras ou reforçado por fibras, compósitos particulados e compósitos estruturais. 0 compósito de fibras é constituído por fibras de um determinado material reforçando uma matriz de outro material, como fibras de carbono, kevlar, vidro, juta em matrizes poliméricas. O compósito particulado é formado por partículas de grandes dimensões de um determinado tipo material dispersam numa matriz de um outro tipo de material, como concreto e asfalto. Por fim, os compósitos estruturais ou laminares são formados por lâminas de diferentes materiais - inclusive compósitos dos dois tipos anteriores -, tais como contra placados, laminados de fibras e resina, e sandwich (RENNY, 2004). 
Diversas indústrias utilizam compósitos em sua cadeia produtiva, como: aeronáutica/aeroespacial, a construção civil, marítima, desportos de alta competição a laser e a indústria automobilística (FURTADO et al., 2014). Inicialmente, a classe desse material foi impulsionada pelas necessidades aeronáuticas e bélicas de materiais que combinassem tanto elevada resistência quanto leveza.

Como já apresentado anteriormente, nos últimos anos, a busca por materiais ecologicamente corretos tem direcionado o surgimento de compósitos de matrizes poliméricas com fibras naturais. Produtos artificiais como o MDF, o aglomerado, o compensado, são exemplos de compósitos inspirados em produtos naturais. Pode-se destacar ainda os cimentícios - tijolo de concreto, o ladrilho hidráulico, placas de cimentício e a fibra de vidro (ABREU, 2015).

Após a explanação técnica e objetiva acerca dos compósitos, parte-se para o objetivo principal da discussão. A seguir, os compósitos são analisados de forma mais subjetiva, considerando sua essência materiais e seus principais aspectos.

\section{Materiais que geram novos materiais}

A união da psicologia, antropologia e design tem gerado ricas discussões e novas metodologias de projeto aos designers. O campo subjetivo dentro do Design tem conquistado o seu espaço com mais veemência desde a década de 90 , principalmente por conta dos estudos em torno do Design Emocional, com o intuito de profissionalizar projetos com foco em emoção (TONETTO, 2011). Neste contexto, os designers buscam desenvolver produtos com maior valor agregado, atentos à sua dimensão estética e funcional, além de seus aspectos simbólicos. Assim, é importante destacar que se a escolha de simples artefatos pode ser guiada por questões emocionais, do mesmo modo, a escolha por materiais para fabricação de artefatos também pode ser determinada por seus atributos subjetivos.

De forma geral, os humanos exercem influência, alterações e impactos apenas com a sua existência, sendo tais ações intensificadas com a sua consciente atuação. Segundo Ingold (2015), os seres humanos estão inseridos em um oceano de materiais, desempenhando um importante papel nas suas transformações. Os seres humanos não são passivos em relação ao meio em que vivem. Todavia, Pollard (2004) complementa que as coisas materiais também não são, sendo processos, e por esta razão, não podem ser capturadas e contidas, pelo contrário, transbordam.

Os materiais que compõem o mundo não estão inertes, recebendo toda e qualquer ação passivamente. É necessário aprender com os materiais, visto que eles são ativos. Desconsiderando o pensamento moderno que subjugam os materiais como tipicamente inanimados, eles são vistos como "os componentes ativos de um mundo-em-formação. Onde quer que a vida esteja acontecendo, eles estão incansavelmente em movimento - fluindo, se deteriorando se misturando e se transformando" (INGOLD, 2015, p. 61). Em conformidade com Simondon (1980), a matéria viva em si é um veículo de energia, opondo-se as teorias de passividade e indeterminação.

Portanto, a agência dos materiais encontra-se consigo mesmo, com a sua própria materialidade, pois o "espírito que as anima não está na, mas é de matéria" (PELS, 2015, p. 62). Desse modo, a matéria é autodesenvolvida na corrente dos materiais existentes, resultando em constantes processos de transformações. Passa-se a analisar qualquer material para além da sua constituição, visto que o poder de agência está com o próprio material. Tim Ingold (2012) 
exemplifica a vitalidade dos materiais em seus fluxos e interações com o meio externo:

\begin{abstract}
Numa estrada asfaltada ou fundação de concreto, nada pode crescer, a menos que haja um abastecimento a partir de fontes remotas. Mas mesmo o mais resistente dos materiais não pode resistir para sempre aos efeitos da erosão e desgaste. A superfície asfaltada, atacada por raízes por baixo e pela ação do vento, chuva e geadas por cima, eventualmente racha e se espedaça, permitindo às plantas crescerem através dela para se misturarem e se ligarem novamente à luz, ao ar e à umidade da atmosfera. Onde quer que olhemos, os materiais ativos da vida estão vencendo a mão morta da materialidade que tenta tolhê-los. (INGOLD, 2012, p. 37)
\end{abstract}

Pode-se observar que as mudanças presentes nos materiais ou objetos não dependem apenas da sua intensidade de utilização e consequente desgaste. Isto é evidenciado na impossibilidade de algo material durar para sempre, mesmo com os melhores esforços de conservacionistas e curadores. Os materiais não estão subjugados à sua função, mas prevalecem sobre qualquer forma de domínio e controle a longo prazo.

Os materiais atuam em um primeiro plano de tal forma que são capazes de sobreviver aos próprios objetos feitos a partir deles. Isto estabelece, inclusive, a possibilidade de reciclagem, visto que o foco muda de objetos acabados para o material de que são feitos, apropriando-se do seu potencial de transformação. Dentro desta discussão, "materiais reciclados são uma 'zona cinzenta', no limite entre o material e o objeto" (BUNN, 1999, p. 21).

É válido ressaltar que os materiais em seu estado mais puro com suas propriedades e especificidades, podem ser combinados, misturados e transformados. O resultado dessa unidade é um material novo com características singulares ou inesperadas, pois "muitos materiais comumente utilizados são obtidos a partir da combinação improvável de ingredientes de uma variedade surpreendente de fontes" (INGOLD, 2015). Portanto, é coerente a ideia de que os materiais podem gerar novos materiais.

Neste âmbito, os compósitos recebem uma agência humana resultante de estudos e testes para posteriores combinações de materiais. A matéria, ainda viva, é induzida a fundir-se com outras, de forma racional e objetiva. O surgimento de compósitos de forma natural e sem agência humana não é descartada neste artigo, contudo aqui discute-se a união de materiais realizada no outro extremo. Ocorre uma agência de mão-dupla, o material sobre 0 agente (designer/cientista/pesquisador) e os mesmo sobre o material. Uma relação bilateral surge neste processo, ocasionando respostas de ambos os lados. Por esta mesma razão, os materiais ou matérias-primas precisam ser acompanhados e observados com maior cautela.

Segundo Noronha (2015), os meios buscados para conter o material de acordo com o objetivo final, podem ser denominados de "medidas de contenção do material", sendo estas um reflexo desta resistência existente do agente ao tentar manter os materiais intactos e inertes em contrapartida ao transbordar iminente do material. A própria mão de obra humana trata-se de um dos princípios que constitui o fluxo de transformação dos materiais, revelando as forças que os modificam ao deixar marcas em tais materiais, como uma rachadura, por exemplo. Como Ingold (2012, p. 36) afirma: o cozinheiro, o alquimista, o pintor ou o ceramista operam contendo os materiais ao combinar e redirecionar fluxos, antecipando a forma do material. É o saber-fazer determinando forma à matéria, e os materiais sendo contidos em todo este processo.

Nesta contenção do material, os designers exercitam o controle sobre o material, todavia, 
também recebem um aprendizado singular na prática do saber-fazer. Este saber-fazer também se caracteriza como um exercício de controle sobre os próprios corpos, próprio intelecto e os materiais dispostos.

Além dos fios de vida presentes nos próprios materiais bem como a atuação humana na combinação de "materiais vivos", é importante considerar as suas caraterísticas particulares. A seguir, a discussão será focada na necessidade de ponderar as propriedades e qualidades dos materiais para a melhor criação de um compósito.

\section{Diálogos entre propriedades e qualidades}

Segundo Pye (1968), cada material tem suas propriedades intrínsecas e cientificamente comprovadas que emergem de acordo com seu uso. Os materiais devem ter as suas propriedades existentes respeitadas afim de exercer seu melhor desempenho.

Entretanto, as propriedades conduzem a outras importantes características dos materiais: as qualidades. Enquanto as propriedades são aspectos objetivos e mensuráveis dos materiais, as qualidades apontam para a subjetividade. As qualidades são consideradas a partir das preferências pessoais dos usuários/manipuladores dos processos. Trata-se, portanto, de um conhecimento adquirido pela percepção sensorial e engajamento prático dos envolvidos.

Para Pye (1968), os materiais são variedades da matéria, com sua existência totalmente independente da presença ou atividades humanas. Novamente salienta-se a vida dos materiais, colocando-os como elementos ativos no mundo físico. Assim, é possível que os materiais sejam além do que realmente se revelam ser ao levar em consideração as suas qualidades. Do mesmo modo, os materiais são aquilo que já são: insubordinados a qualquer caracterização humana. Assim, as propriedades e qualidades são divergentes da seguinte forma: propriedades são propriedades da matéria e as qualidades são ideias opostas (ou congruentes) que a mente projeta, ou seja, produções das relações estabelecidas no processo de correspondência entre humanos e nãohumanos, como afirma Ingold (2011).

Os compósitos proporcionam diferentes qualidades a partir das propriedades existentes. Do ponto de vista técnico, as propriedades dos materiais devem ser criteriosamente analisadas para uma eficiente combinação em um compósito. Além disso, os materiais podem ser submetidos a diversos testes para mensurar as propriedades existentes, tais como densidade, elasticidade, condutividade térmica, etc (INGOLD, 2015). Porém, as qualidades em um compósito de materiais são discorridas de acordo com a visão particular ou propósito dos idealizadores, sendo estes pesquisadores, designers ou outros agentes que estudam os materiais.

Vale destacar que a possibilidade de escolha dos materiais em um compósito e até mesmo o controle das forças que agem sobre os materiais envolvidos no processo, "de conter o transbordamento das coisas" (NORONHA, 2015, p. 166), proporciona uma tomada de decisões acerca da produção de um novo material a partir dos ideais do agente. Tal argumento não exclui a ideia da autonomia existente nos materiais, mas acrescenta uma outra consideração relevante, isto é, a forma pela qual os humanos enxergam os materiais independente de suas propriedades inerentes. Esta projeção para alcançar algum objetivo através dos materiais estimula o desenvolvimento de novos materiais. 
Partindo do princípio de que os materiais estão em constante fluxo de vida com interações entre si, denota-se que as propriedades também não podem ser consideradas como características físicas fixas, colocando em questão parte das argumentações de Peter Pye. Pelo contrário, os materiais são processuais e relacionais, não sendo "objetivamente determinadas nem subjetivamente imaginadas, mas experimentadas" (INGOLD, 2015, p. 65). Dessa forma, as propriedades e qualidades são mutáveis, visto que os materiais possuem a capacidade de fluir, se misturarem e se modificarem.

Ao agrupar materiais disponíveis ou com possibilidade de reciclagem, proporciona-se desdobramentos de acordo com os resultados dos experimentos. Os compósitos assumem diferentes aspectos ao se tornar um novo material com uma combinação de propriedades, visto que este é o principal objetivo de sua produção. Todavia, também possibilita o surgimento de qualidades a partir da combinação e objetivo dos seus agentes. O compósito promove a singularidade em ambos os eixos, bem como inúmeras premissas para a inovação.

\section{Considerações Finais}

Os materiais influenciam desde a ordem mundial à vivência particular de cada indivíduo. Como já foi dito anteriormente, o poder de influência e transformação dos materiais é realizada por meio dos seus fios vitais de existência - remetendo à vida presente em cada material, bem como suas interações, forças e fluxos que dão forma ao trabalho (INGOLD, 2012). Este artigo enfatiza que não apenas os seres humanos tornam-se responsáveis por moldar a matéria-prima, mas os materiais moldam a o pensar e o agir do homem, visto que existe uma livre agência dos materiais ao redor. Existe um mundo de materiais, antes mesmo do mundo material.

Desse modo, é notória a importância de os materiais receberem um enfoque maior tanto em pesquisas teóricas como pesquisas aplicadas. As breves discussões realizadas neste artigo demonstrou a abundância de contribuições que uma reflexão subjetiva acerca dos materiais pode alavancar no meio acadêmico. O desenvolvimento de uma perspectiva simbólica acerca dos materiais presentes no mundo, impulsiona diferentes posturas, inclusive, de ordem prática por designers.

O compósito como objeto específico de análise, aponta a necessidade de uma abordagem mais criteriosa na seleção de materiais, considerando sua vitalidade, qualidades e propriedades. Assim, uma simples combinação de materiais complexos em sua essência, possibilitam uma gama de expectativas e resultados aos profissionais e pesquisadores do vasto campo interdisciplinar de materiais.

A partir das reflexões de Tim Ingold, conclui-se que os compósitos não apenas consistem nas junções de dois ou mais materiais diferentes para a formação de um novo material, mas explana uma singular percepção e correspondência entre as pessoas e materiais.

\section{Agradecimentos}

A apresentação deste artigo no evento foi financiada pelo edital Participação em apoio científico da FAPEMA (Fundação de Amparo à Pesquisa e Desenvolvimento Cientifíco e Tecnológico do Maranhão). 


\section{Referências}

ASHBY, M. F.; JOHNSON, K. Materials and design: the art and science of material selection in product design. Amsterdam: Elsevier/Butterworth- Heinemann, 2010.

BEYLERIAN, G. M.; DENT, A. Ultra materials: how materials innovation is chanching the world. Kingdom: Thame \& Hudson, 2007.

BUUN, S. The importance of materials. Journal of Museum Ethnography, vol. 11, p; 15-28, 1999.

CALEGARI, E. P., \& DE OLIVEIRA, B. F. Um estudo focado na relação entre design e materiais. Projetica, 4(1), 49, 2013. Disponível em: https://doi.org/10.5433/2236-2207.2013v4n1p49. Acesso em: 18 out. 2017.

CALEGARI, E. P., \& OLIVEIRA, B. F. DE. Aspectos que influenciam a seleção de materiais no processo de design. ARCOS DESIGN, 8, 1-19, 2014. Disponível em: http://www.epublicacoes.uerj.br/index.php/arcosdesign. Acesso em: 20 out. 2017.

CALLISTER JUNIOR, William D.; RETHWISCH, David. G. Materials science and engineering: An introduction. 8. ed. New Jersey: Wiley, 2008.

CARDOSO, Rafael. Design, cultura material e o fetichismo dos objetos. Revista Arcos (ESDI/UERJ), Rio de Janeiro, v. 1, n. 1, p. 14-39, 1998.

CARDOSO, Rafael. Uma introdução à história do design. São Paulo. Edgar Blücher, 2000.

DIAS, M. R. A. C. Percepção dos materiais pelos usuários: modelo de avaliação permatus. 2009. Tese (Doutorado em Engenharia e Gestão do Conhecimento) - Programa de Pós-Graduação em Engenharia e Gestão do Conhecimento, Universidade Federal de Santa Catarina, 2009.

FARIAS, J A., \& SANTOS, D. M. Avaliação de compósito obtido de resíduos da construção civil e pet. 12 P\&D 2016 - Congresso Brasileiro de Pesquisa e Desenvolvimeno em Design , 8, 1-15, 2016. Disponível em: < http://pdf.blucher.com.br.s3-sa-east1.amazonaws.com/designproceedings/ped2016/0363.pdf>. Acesso em: 23 out. 2017.

FERRANTE, M.; WALTER, Y. A materialização da ideia: noções de materiais para design de produto. Rio de Janeiro: LTC, 2010.

INGOLD, Tim. Estar vivo: ensaios sobre movimento, conhecimento e descrição. Petrópolis, RJ: Vozes, 2015.

INGOLD, Tim et al. Diálogos Vagueiros: Vida, Movimento e Antropologia. Entrevista com Professor T. Ingold. Ponto Urbe. Revista do núcleo de antropologia urbana da USP, n. 11, 2012.

INTERNATIONAL COUNCIL OF SOCIETIES OF INDUSTRIAL DESIGN - ICSDI. Definition of design. Disponível em: <http://bit.ly/9YDndi>. Acesso em: 18 nov. 2017.

LÖBACH, B. Design Industrial: bases para a configuração dos produtos industriais. São Paulo: Editora Edgard Blücher, 2001.

LOFTHOUSE, V.A. Investigation into the Role of Core Industrial Designers in Ecodesign Projects. Design Studies, 25(2):215-227, 2004. Disponível em: <http://dx.doi.org/10.1016/j.destud.2003.10.007>. Acesso em: 24 out. 2017. 
LOFTHOUSE, V.A. Ecodesign tools for designers: de- fining the requirements. Journal of Cleaner Production, 14(15-16):1386-1395, 2006.2 Disponível em: <http://dx.doi.org/10.1016/j.jclepro.2005.11.013>. Acesso em: 24 out. 2017.

MANZINI, Ezio. A matéria da invenção. Tradução de Pedro Afonso Dias. Lisboa: Centro Português de Design, 1993.

MANZINI, E.; VEZZOLI, C. O desenvolvimento de produtos sustentáveis: os requisitos ambientais dos produtos industriais. São Paulo: Edusp, 2002.

NORONHA, Raquel Gomes. Dos quintais às prateleiras: as imagens quilombolas e a produção da louça em Itamatatiua - Alcântara - Maranhão. 289f. Tese (Doutorado em Ciências Sociais) Instituto de Filosofia e Ciências Humanas - Programa de Pós-Graduação em Ciências Sociais. Universidade do Estado do Rio de Janeiro, Rio de Janeiro, 2015.

PAZMINO, A. V. Uma reflexão sobre Design Social, Eco Design e Design Sustentável. I Simpósio Brasileiro de Design Sustentável, 1-10, 2017.

PELS, P. The Spirit of matter: on fetish, rarity, fact and fancy. In: SPYER, P. (ed.). Border Fetishisms: Material Objects in Unstable Spaces. Londres: Routledge, p. 91-121, 1998.

POLLARD, J. The art of decay and the transformation of substance. In: RENFREW, C.; GOSDEN, C.; DEMARRAIS, E. (Ed.). Substance, memory, display. Cambridge: McDonald Institute for Archaeological Research, p. 47-62, 2004.

PYE, David. The Nature and Art of Workmanship. Cambridge, UK: Camb. Univ. Press, 1968.

SHACKELFORD, James F. Ciência dos materiais. 6.ed. São Paulo: Pearson, 2012.

SIMONDON, G. On the Mode of Existence of Technical Objects. University of Western Ontario (Ed. de J. Hart; Trad. de N. Mellamphy, 1980). Traduzido de Du Mode d'existence des Objects Techniques. Paris: Aubier Montaigne, 1958.

TONETTO, Leandro; COSTA, Filipe. Design Emocional: conceitos, abordagens e perspectivas de pesquisa. Strategic Design Research Journal, volume 4, number 3, September-December, 2011. Disponível em: revistas.unisinos.br/index.php/sdrj/article/view/4492/1716. Acesso em: 20 mar. 2018.

VEZZOLI, Carlo. Design per la sostenibilità: una disciplina (sempre più) articolata, in Vezzoli C., Tamborrini P. (a cura di), Design per la sostenibilità. Strumenti e strategie per la decade "Educazione per lo sviluppo sostenibile, Nazioni Unite (2005-2014)", patrocinato da Nazioni Unite (DESD), Commissione Nazionale UNESCO e provincia di Milano, LlibreriaClup editore, ISBN 978-88-7090949-4, Milano, 2007a, pp. 31-45. 